\section{Carrier detection through the use of abnormal deletion junction fragments in a case of haemophi- lia B involving complete deletion of the factor IX gene}

We previously reported a case of carrier detection by gene dosage analysis in a family with haemophilia $\mathrm{B},{ }^{1}$ where the affected member had severe factor IX deficiency (with an inhibitor) as a result of a deletion of his factor IX gene.

Subsequent analysis has shown that the severe haemophilia B patient referred to by Peake et l $^{1}$ has an X chromosome deletion of minimum size $114 \mathrm{~kb}$ that includes the entire factor IX gene. ${ }^{2}$ The isolation of further $3^{\prime}$ flanking probes ( G G Brownlee, D S Anson, unpublished observations) has enabled us to locate the $3^{\prime}$ breakpoint of this deletion at a position $145 \mathrm{~kb} 3^{\prime}$ to the start of the factor IX gene. Abnormal junctional fragments detected at the breakpoint have been used in a carrier study (figure). The patient IV.1 shows a new $9.5 \mathrm{~kb}$ fragment instead of the normal $10.5 \mathrm{~kb}$ fragment after digestion of his DNA with the restriction enzyme TaqI and probing with genomic probe W2C Bam $6.6 \mathrm{~kb}$ (a $3^{\prime}$ flanking probe derived from sequences 146 to $152 \mathrm{~kb} 3^{\prime}$ to the start of the factor IX gene). This fragment was not seen in 18 normal $X$ chromosomes, and abnormal fragments were also observed in DNA from the patient when using this probe and restriction enzymes $H$ ind III, $B g I, B a m H I$, and $X b a I$. The results strongly suggest that the new $9.5 \mathrm{~kb}$ TaqI band is indeed a result of the gene deletion and not of an infrequently occurring restriction fragment length polymorphism.

The patient's mother (III.2) and sister (IV.2) both show this abnormal band together with the normal $10.5 \mathrm{~kb}$ band, and are therefore carriers of this haemophilia B trait. These results confirm the earlier carrier studies based on phenotypic data and gene dosage. ${ }^{1}$

The observation that the patient's grandmother and great grandmother (II.1 and I.1), together with four other female family members, do not show abnormal fragment patterns with this junctional probe could be taken to confirm their non-carrier status, in agreement with our previous studies in the family. However, it is important to note a recent report of germinal mosaicism in the mothers of two haemophilia A patients. ${ }^{3}$ In this case the defect (deletion) in the affected child's factor VIII gene was different from that in the mother's altered gene. Furthermore, it was shown that the mother's abnormal gene could be inherited, as well as its more modified form. Thus, for some haemophilia deletion cases one cannot assume that the boundaries of a deletion will be the same in all affected males and carrier females within a given family.

Received for publication 28 October 1987. Accepted for publication 29 November 1987.

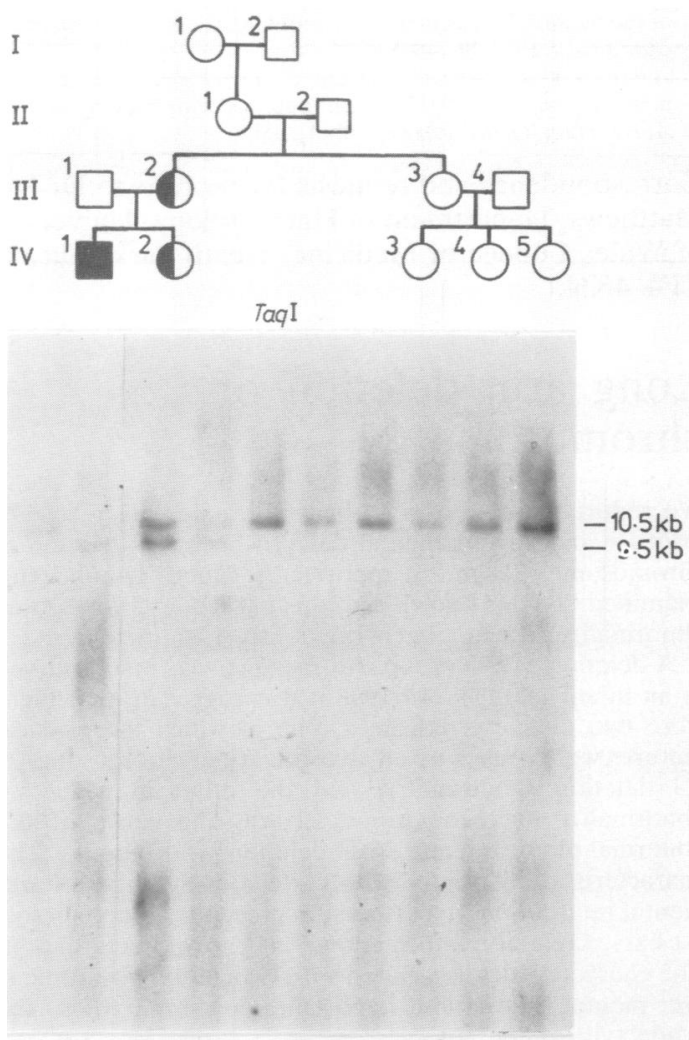

NM IV. 1 III. 2 IV.2 I. 1 II. 1 IV.3 III.3 IV.4 IV.5

W2C Bam6.6kb

FIGURE Family pedigree and Southern blot analysis. DNA was digested with TaqI and probed with the factor IX 3' flanking probe W2C Bam 6.6 kb. NM is DNA from a normal male.

Although we have no evidence that the above has occurred in this family, and, in fact, our previous results would strongly suggest that it has not, it is important to emphasise the need to combine as much phenotypic and genotypic data as possible for accurate carrier detection in haemophilia.

R J Matthews*, I R Peake*, A L Bloom*, AND D S Anson $\dagger$ *Department of Haematology, University of Wales College of Medicine, Cardiff; and tSir William Dunn School of Pathology, South Parks Road, Oxford. 


\section{References}

1 Peake IR, Furlong BL, Bloom AL. Carrier detection by direct gene analysis in a family with haemophilia B (factor IX deficiency). Lancet 1984;i:242-3.

2 Matthews RJ, Anson DS, Peake IR, Bloom AL. Heterogeneity of the factor IX locus in nine haemophilia B inhibitor patients. $J$ Clin Invest 1987;79:746-53.

${ }^{3}$ Gitschier J. An unusual pattern of inheritance of rearrangements in the factor VIII gene in a family with haemophilia A. Am J Hum Genet 1986;39(suppl):200A.

Correspondence and requests for reprints to Dr $\mathrm{R} \mathrm{J}$ Matthews, Department of Haematology, University of Wales College of Medicine, Heath Park, Cardiff CF4 4XN.

\section{Long arm deletion of chromosome 22}

We report the case of a 13 year old male with a seizure disorder and developmental delay, who has a deletion of chromosome 22 in all peripheral blood lymphocytes examined. To our knowledge, this particular chromosome abnormality has not been previously identified.

A deletion of a $G$ group chromosome was first observed in an infant in $1964 .{ }^{1}$ In 1968 it was suggested that there were two distinct syndromes, one in which the physical features were caused by an abnormality of chromosome 21 ( $G$ deletion syndrome $\mathrm{I}$ ) and the other in which an abnormality of chromosome 22 was the cause of the abnormal physical features ( $G$ deletion syndrome II). The characteristics associated with $\mathrm{G}$ deletion syndrome $\mathrm{I}$ are: mental retardation, hypertonia, microcephaly, large or low set ears, skeletal malformations, and growth retardation. The characteristics associated with $\mathrm{G}$ deletion syndrome II are: mental retardation, hypotonia, epicanthic folds, and syndactyly of the toes. ${ }^{2}$

These chromosome abnormalities and their associated physical characteristics are somewhat variable, as noted by Maeda et al. ${ }^{3}$ They concluded that the physical features associated with $G$ deletion syndrome $I$ are constant and represent a clinically distinct syndrome. The physical characteristics associated with $\mathrm{G}$ deletion syndrome II, on the other hand, appear to be somewhat variable.

We describe here the clinical and cytogenetic findings in a 13 year old male who has a deletion of the long arm of chromosome 22 . The patient was born after a 10 month pregnancy to a deaf, 18 year old, G1P0 woman and a deaf 17 year old man. The child sat alone at 12 months, crawled at 18 months, and walked at three years. He frequently exhibits physically aggressive behaviour. The child has poor communication skills that cannot be attributed to his parents' lack of speech. Auditory sensitivity for simple speech and tonal stimuii were assessed and hearing impairment as a contributing factor to his speech delay was ruled out. Other areas of development, including gross and fine motor development, self help skills development, and cognitive development were also delayed. Physical exami-

Received for publication 19 December 1987.

Revised version accepted for publication 17 February 1988
FIGURE $\quad G$ banded example of $22 q-$.

nation revealed bilateral epicanthic folds, as well as broad fingers and thumbs. No other external abnormalities were noted.

All metaphases examined (122) showed a $46, X Y, \operatorname{del}(22) \stackrel{\Phi}{\stackrel{\Phi}{-}}$ (pter $\rightarrow q 12:)$ complement (figure). The chromosomes $\mathrm{gf}_{\overrightarrow{0}} \overrightarrow{\mathrm{C}}$ both parents were normal.

The clinical features found in our patient with a deletion of chromosome 22 do not coincide completely with the. observed in $\mathrm{G}$ deletion syndrome II. While our patientes mentally retarded and has epicanthic folds, he does not have syndactyly of the toes or hypotonia, both of which were observed in all cases of $G$ deletion syndrome II. In

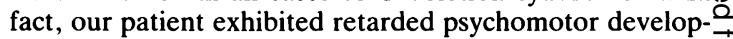
ment which is associated with $\mathrm{G}$ deletion syndrome $\mathrm{I}$. This is consistent with the variability reported in $\mathrm{G}$ deletion 3 syndrome II by other authors. A compilation of additional? cases is necessary to clarify the syndrome associated witho deletion of the long arm of chromosome 22.

Gary Kirshenbaum, Mark Chmura, AND Douglas P Rhone윽 Department of Pathology, Illinois Masonic Medical Center, $\bigcirc$ Chicago, Illinois, USA.Э

\section{References}

1 Lejeune J, Berger R, Rethoré MO, et al. Monosomie partielle음 pour un petit acrocentrique. $C R$ Acad Sci [D] (Paris) 1964;259:4187-90.

2 Warren RJ, Rimoin DL, Summitt RL. Identification by ${ }^{\circ}$ fluorescent microscopy of the abnormal chromosomes associ- $\mathbb{O}$ ated with the $\mathrm{G}$ deletion syndromes. Am J Hum Genet N 1973;25:77-81.

3 Maeda T, Ohno M, Nishida H. Clinical and cytogenetic studies of two infants with partial monosomy. Hum Genet 1977;35 255-9.

Correspondence and requests for reprints to $\mathrm{Dr} G \stackrel{\mathscr{\mathscr { C }}}{+}$ Kirshenbaum, Department of Pathology, Illinois Masonic Medical Center, 836 Wellington Avenue, Chicago, Illinois우 60657, USA. 